\title{
An Approach to Scientific and Legislative Governance of Solar Radiation Modification Research in the United States
}

\author{
$\underline{\text { Neva Luthria }}^{1}, \underline{\text { Steven L. Farrell}}^{2}, \underline{\text { Ingrid Joylyn Paredes }}^{2}$ \\ ${ }^{1}$ New York University, Gallatin School of Individualized Study, New York, NY \\ ${ }^{2} \mathrm{New}$ York University, Tandon School of Engineering, Brooklyn, NY \\ https://doi.org/10.38126/JSPG180207 \\ Corresponding author: nevaluthria@nyu.edu \\ Keywords: climate change; geoengineering; solar radiation management; IPCC; UN; COP26
}

\begin{abstract}
Executive Summary: The climate crisis requires immediate, rapid, and responsible action across all sectors. Without implementation of aggressive mitigation strategies, the Intergovernmental Panel on Climate Change has warned that we will fail to remain below the catastrophic global warming threshold of $1.5^{\circ} \mathrm{C}$. Climate engineering technologies, such as carbon dioxide removal and solar radiation modification (SRM), have been proposed as mitigation strategies, but have not been deployed at scale. In addition to the scaling problems, SRM technologies, particularly stratospheric aerosol injection, have faced criticism over ethical implications of their implementation. The United Nations (UN) efforts to introduce international governance over SRM have been blocked by several countries, including the United States (US). Meanwhile, domestic researchers in the US have independently pursued small-scale experiments. The effects of these experiments remain uncertain, yet, if scaled, extend to non-consenting countries, including those already more susceptible to the climate crisis. We recommend that the US (1) stop blocking the UN from pursuing research into the impacts of SRM to allow for equitable governance options to be explored and (2) establish a national advisory committee on solar geoengineering.
\end{abstract}

\section{Background}

According to the Intergovernmental Panel on Climate Change (IPCC), the world is currently on course to surpass the $1.5^{\circ} \mathrm{C}$ threshold of global warming unless proactive and thorough climate mitigation strategies are put into place (Rogelj et al. 2018). The IPCC warns that passing this threshold could result in irreversible changes to our planet, including frequent droughts, wildfires, hurricanes, flooding, and food shortages, but notes a lack of literature on climate mitigation strategies specific to preventing our planet from reaching this point of no return(Rogelj et al. 2018). Climate engineering technologies that alter the planet's climate system via carbon dioxide removal and solar radiation modification (SRM) have been proposed as possible mitigation strategies which, in tandem with measures to reduce greenhouse gas emissions, could prevent our planet from reaching the $1.5^{\circ} \mathrm{C}$ threshold. However, climate engineering technologies still remain unproven at a global scale (de Coninck et al. 2018). Carbon dioxide removal is effective, but not feasible to scale sufficientlycommercial carbon capture technologies currently remove up to only 2 tons of carbon dioxide from the air per day (Climeworks 2020; Carbon Engineering 2020). The IPCC estimates that even while taking measures to reduce emissions, we would need to capture at least 100 billion tons of carbon dioxide by 2100 to remain under the warming threshold (Masson-Delmotte et al. 2018). This leaves stratospheric aerosol injection as the primary climate engineering method with the potential to significantly cool the planet.

A subset of SRM, stratospheric aerosol injection, remains largely unexplored, since both the feasibility of SRM technology and the global response to such an intervention is unknown. While large-scale 
operations only exist as proposals, researchers have looked to volcanic eruptions, which inject sunlightreflecting sulfuric acid aerosols into the atmosphere, for analogues. For example, the Mount Pinatubo eruption of 1991 injected fifteen to twenty million tons of sulfuric acid particles into the atmosphere, cooling the planet's average temperature by $0.6^{\circ} \mathrm{C}$ during the following 15 months (NASA Langley Research Center Aerosol Research Branch 2011).

Despite growing research interest, governance of SRM remains uncertain, which could lead to unintended consequences for economies and vulnerable communities (Reynolds 2019). In 2018, the IPCC estimated that stratospheric aerosol injection would cost from $\$ 1$ billion to $\$ 10$ billion per year, excluding the potential financial impacts from side-effects such as altering precipitation patterns or disruption to stratospheric chemistry (de Coninck et al. 2018). Ethical concerns include international responsibilities for implementation, compensation for negatively impacted populations, procedural justice in decision-making, and informed consent from communities (de Coninck et al. 2018). The current lack of governance, large cost, and potential ethical concerns may have contributed to SRM's exclusion from the IPCC's outline of emission scenarios (Rogelj et al. 2018).

No national or international solar geoengineering legislation has been formalized yet, nor are there any restrictions on conducting solar geoengineering research. At a global scale, the United Nations (UN) outlawed "military or any other hostile use of environmental modification techniques" in 1978 after the United States (US) weaponized cloud seeding in the late 1960 s by creating monsoon floods in Vietnam to hinder enemy troops during the Vietnam War (Deputy Under Secretary of State for Political Affairs to Secretary of State Rusk, 1967). However, specific governance of SRM, particularly stratospheric aerosol injection, has not been established. In 2019, Switzerland and nine other nations requested that the UN Environment Programme further research the impacts of SRM, require transparency of SRM research, and construct potential international legislation on the matter. However, the US, Saudi Arabia, and Brazil blocked the resolution, facing criticism from environmental groups and scientists. One speculative factor contributing to this opposition might be that these countries are three of the world's largest oil supplying nations (US Energy Information Administration 2017); the deep reliance of their economies on the fossil fuel industry may have motivated them to push for unregulated SRM as a means to offset continued fossil fuel burning as an alternative to reduced emissions and clean energy. However, the three countries formally justified their decision by insisting only the IPCC should be responsible for such matters. However, the US and Saudi Arabia-which have the world's two highest rates of climate change denial (Smith 2019) — had both previously undermined and critiqued the IPCC, failing to acknowledge its 2018 report on the inevitability of $1.5^{\circ} \mathrm{C}$ warming without intervention. Their decision to formally acknowledge the IPCC report has hindered the international community in holding nations accountable for the scale of climate action demanded by the report (Chemnick 2019).

Although lacking structured oversight or international mandate, the US has still explored SRM research. In December 2019, Congress allocated funding to SRM research for the first time, providing $\$ 4$ million to the National Oceanic and Atmospheric Administration (H.R. 1158. 116 th Cong. 2019). California Representative Jerry McNerney introduced geoengineering oversight bills in both 2017 and 2019 in hopes that "appropriate authorities are leading this initiative to ensure safe practices are being promoted and proper governance is being applied," but neither provision has been signed into law (Congressman Jerry McNerney 2019). In this uncertain context, researchers at Harvard University have launched the most prominent SRM project, the Stratospheric Controlled Perturbation Experiment (SCoPEx). The project must adhere to Federal Aviation Administration regulations and provisions of the National Environmental Policy Act, but no specific national-level regulation exists for this field of work. In the absence of structured guidance, the investigators have assembled an independent advisory committee comprising members who are removed from its researchers, including professors and researchers from other colleges, policy advisors, and renewable energy leaders (SCoPEx Advisory Committee 2020), but no international researchers.

With a lack of domestic and international policy, researchers will continue to self-govern research into SRM. As it stands, any group with sufficient funding 
could pursue an SRM experiment with very minimal legal, ethical, or environmental guidelines and standards. This is inequitable and potentially quite dangerous. Developing countries tend to be more susceptible to desertification, rely heavily on climatesensitive sectors like agriculture, and lack infrastructure to deal with extreme weather events (Eckstein 2019). As such, they would also be the countries most impacted by, and least able to manage, negative externalities from SRM research projects. It would be disastrous if, by means of geoengineering, one country were responsible for drought, food shortages, and resulting political instability in another. To guard against such scenarios, governance proposals must be equitable. With this understanding, recent research has reviewed global governance proposals, showing the need for increasing public dialogue around SRM and engaging active stakeholders to create societal legitimacy of the field (Frumhoff and Stephens 2018).

\section{Policy recommendations}

To address the current lack of structured and equitable oversight of SRM research, we make two recommendations to US legislators who have an interest in stemming climate change. These recommendations are evaluated and presented according to the following criteria:

- Program Effectiveness: the scope and impact of a policy pathway towards promoting climate mitigation technologies while providing good scientific governance.

- Program Equity: the fairness in which a policy pathway may protect at-risk groups affected by climate change or the impacts of SRM.

- Feasibility of Implementation: the ease with which a pathway may be imposed, given current administrative resources and legislative agendas.

We propose the acceptance of UN guidance towards SRM and the establishment of a national advisory committee to steer domestic legislation and discuss the opportunities and obstacles of each in regards to the criteria.

\section{i. Allow UN guidance and regulation}

We recommend that the US accept the findings of the IPCC 2018 Special Report, welcoming the IPCC's findings into climate negotiations, and allow the UN to guide and regulate solar geoengineering research.

\section{Opportunities}

Accepting and welcoming the IPCC findings into UN climate negotiations would help establish the US' credibility in addressing the climate crisis. Acceptance would also align with the climate action plan put forward by the Biden administration, which set a goal of "net zero" carbon emissions by 2050 (Joe Biden for President 2020). As this would potentially guide the domestic legislative agenda, Congress may pass a resolution to recognize the findings of the IPCC report.

In accepting the proposal for the UN to further research and regulate SRM, the US would no longer hinder equitable exploration of governance. It is also imperative that the US work effectively on climate action on the international stage, especially regarding SRM. As weather itself is not bound by national borders, any effects on stratospheric weather, however localized within the US, may impact the oceans or the lands of its neighbors. International connection through the UN remains an important tool towards maintaining equity for neighboring nations in addressing climate change. Management by the UN would additionally prevent the nationalization of large-scale SRM efforts. By starting at the international level, the cross-border impacts would be the forefront focus when crafting regulations and agreements.

\section{Obstacles}

While this pathway would best foster international representation and diverse stakeholders, it depends solely on the UN for guidance and does not offer an effective program for enforcement in US-based SRM programs. Additionally, while it may better address issues of cross-border impacts, it does not necessarily set out to address the local impacts across different communities of the US and would therefore need further bolstering domestically.

\section{ii. Establish national advisory committee}

We recommend that the US establish a national advisory committee through legislation to guide regulation and investigate SRM impacts domestically and abroad, and to promote cross-border collaborative research. 


\section{Opportunities}

Such a committee would investigate the potential risks and impacts associated with SRM research ranging from laboratory-scale to the regional level. Based on its findings, it would make legislative recommendations to lawmakers regarding SRM rulemaking and issue guidelines to researchers for best practices in conducting research. The domestic committee would best function with a combination of lawmakers, scientists, and public stakeholders to guide and regulate research beyond small-scale laboratory experiments, where such research could begin to impact the local environment and beyond as scale grows. As with the previous option, a congressional resolution would be passed to establish this committee to guide future legislation.

Under this recommendation, US-based research can be promoted while undesired negative impacts can be recognized and avoided. Given the wide variety of climates and biomes across the country, this would be most effective in protecting land and people with regulations tailored to the regional or local level. Under the Biden administration's climate action plan, implementing such a committee is feasible through legislative powers. This committee could be used not only to guide federal legislation, but also provide input or support for local legislation regarding such research.

\section{Obstacles}

The main hurdle for this option is the lack of international connection. Domestically, impacts on communities located near testing locations may be addressed, but impacts across national borders would be difficult to legislate alone. Therefore, it would be absolutely necessary to include both domestic and international stakeholders to address this shortcoming in the interest of equity, potentially going so far as to promote international collaborative research initiatives in order to unify resulting

\section{References}

"Advisory Committee Members." 2020. SCoPEx Advisory Committee, December 15, 2020. https://scopexac.com/advisory-committeemembers/.

Carbon Engineering. 2020/ "FAQs about Our Carbon Removal Technology." Accessed December 20, 2020.

https://carbonengineering.com/frequentlyasked-questions/. research guidelines and regulations. For example, US policies should be developed in partnership with Canada, Mexico, and Central America; the fruits of these efforts could then serve as a model for stateand regional-level policies and coordination, facilitating responsible SRM research both domestically and internationally. Furthermore, as with the SCoPEx project, including scientists and engineers versed in atmospheric science on any sort of advisory committee would be vital to interpreting the research needs, opportunities, and potential impacts.

\section{Conclusions}

Aggressive action is vital to addressing the climate crisis; action through SRM presents an opportunity to reduce the severity of climate change and may prove highly effective as further research is conducted. However, further research in SRM is needed, and responsible research is imperative. This is especially true given the potential for damaging side-effects on the regional environment and our global ecosystems. If the US continues "business as usual," it virtually eliminates pathways towards both effective, equitable governance in SRM and wide-ranging opportunities to responsibly reduce the impacts of the climate crisis. We therefore recommend that the US accept the findings of the IPCC report into UN climate negotiations, allow the UN to guide research into SRM, and establish a national advisory committee to address domestic research. The obstacles for a potential advisory committee can be addressed through the inclusion of public and foreign stakeholders as well as scientists to interpret research and potential impacts. By understanding the risks and creating standards for the responsible conduct of SRM research, local populations and nonconsenting regions can be protected from deleterious climate impacts associated with SRM as research continues.

Chemnick, Jean. 2019. "U.S. Blocks U.N. Resolution on Geoengineering." Scientific American, March 15, 2019.

https://www.scientificamerican.com/article/u-sblocks-u-n-resolution-on-geoengineering/.

Climeworks. 2020. "Why Remove CO2 via Direct Air Capture? FAQs, Scientific Papers and Policy Reports." Accessed December 20, 2020. https://www.climeworks.com/faq-about-directair-capture. 
de Coninck, H., A. Revi, M. Babiker, P. Bertoldi, M. Buckeridge, A. Cartwright, W. Dong, J. Ford, S. Fuss, J.-C. Hourcade, D. Ley, R. Mechler, P. Newman, A. Revokatova, S. Schultz, L. Steg, and T. Sugiyama, 2018: Strengthening and Implementing the Global Response. In: Global Warming of $1.5^{\circ} \mathrm{C}$. An IPCC Special Report on the impacts of global warming of $1.5^{\circ} \mathrm{C}$ above pre-industrial levels and related global greenhouse gas emission pathways, in the context of strengthening the global response to the threat of climate change, sustainable development, and efforts to eradicate poverty.

Deputy Under Secretary of State for Political Affairs to Secretary of State Rusk. 1967. Weather Modification in North Vietnam and Laos (Project Popeye), Foreign Relations of the United States, 1964-1968, Volume XXVIII, Laos, Document 274. https://history.state.gov/historicaldocuments/fr us1964-68v28/d274.

Eckstein, David, Vera Künzel, and Laura Schäfer. 2019. Issue brief. Global Climate Risk Index 2020. Berlin: Germanwatch e.V..

"Frequently Asked Questions." 2020/ U.S. Energy Information Administration. Accessed December 21, 2020. https://www.eia.gov/tools/faqs/faq.php?id=709 $\underline{\mathrm{t}=6}$.

Frumhoff, Peter C., and Jennie C. Stephens. 2018. "Towards Legitimacy of the Solar Geoengineering Research Enterprise." Philosophical Transactions of the Royal Society A 376, no. 2119. https://doi.org/10.1098/rsta.2016.0459.

"Global Effects of Mount Pinatubo." 2011. NASA Langley Research Center Aerosol Research Branch, June 15 , 2011. https://earthobservatory.nasa.gov/images/1510 Lglobal-effects-of-mount-pinatubo.

H.R. $1158 . \quad 116^{\text {th }} \quad$ Cong. 2019. https://www.congress.gov/bill/116thcongress/house-bill/1158.
IPCC,.2018: Summary for Policymakers. In: Global Warming of $1.5^{\circ} \mathrm{C}$. An IPCC Special Report on the impacts of global warming of $1.5^{\circ} \mathrm{C}$ above pre-industrial levels and related global greenhouse gas emission pathways, in the context of strengthening the global response to the threat of climate change, sustainable development, and efforts to eradicate poverty. World Meteorological Organization, Geneva, Switzerland, 32.

"Plan for Climate Change and Environmental Justice." 2020. Joe Biden for President: Official Campaign Website, October 29, 2020. https://joebiden.com/climate-plan/.

"Rep. McNerney Introduces Legislation to Authorize Atmospheric Climate Intervention Research." 2019. Congressman Jerry McNerney, December 19, 2019. https://mcnerney.house.gov/mediacenter/press-releases/rep-mcnerney-introduceslegislation-to-authorize-atmospheric-climate.

Reynolds, Jesse L. 2019. "Solar Geoengineering to Reduce Climate Change: A Review of Governance Proposals." Proceedings of the Royal Society A 475, no.

2229. https://doi.org/10.1098/rspa.2019.0255.

Rogelj, J., D. Shindell, K. Jiang, S. Fifita, P. Forster, V. Ginzburg, C. Handa, H. Kheshgi, S. Kobayashi, E. Kriegler, L. Mundaca, R. Séférian, and M.V. Vilariño, 2018: Mitigation Pathways Compatible with $1.5^{\circ} \mathrm{C}$ in the Context of Sustainable Development. In: Global Warming of $1.5^{\circ} \mathrm{C}$. An IPCC Special Report on the impacts of global warming of $1.5^{\circ} \mathrm{C}$ above pre-industrial levels and related global greenhouse gas emission pathways, in the context of strengthening the global response to the threat of climate change, sustainable development, and efforts to eradicate poverty.

Smith, Matthew. 2019. "Most People Expect to Feel the Effects of Climate Change, and Many Think It Will Make Us Extinct," September 13, 2019. https://today.yougov.com/topics/science/article s-reports/2019/09/16/global-climate-changepoll.

Neva Luthria is a senior at New York University's Gallatin School of Individualized Study. Her academic concentration studies the intersection of physics, chemistry, and strategy. At the Hybrid Nanomaterials Laboratory within NYU's Tandon School of Engineering, she conducts research on nanoparticle thin films for the electrocatalysis of carbon dioxide to alcohol fuels.

Steven L. Farrell received his B.S and M.S. in Chemical Engineering from Drexel University, and is pursuing a Ph.D. in Materials Chemistry at the New York University Tandon School of Engineering as a member of the Hybrid Nanomaterials Laboratory. He studies two-dimensional nanostructures and materials for sustainable catalysis applications and previously was a coordinator of NYU's Science Policy and Diplomacy course. Additionally, he has coordinated the \#StreamForScience digital event collaboration with March for Science NYC. 
Ingrid Joylyn Paredes is a Ph.D. candidate in chemical engineering at the New York University Tandon School of Engineering in Brooklyn, NY as a member of the Hybrid Nanomaterials Laboratory. The focus of her thesis research is the development of novel nanomaterial systems for clean energy technologies. She currently serves as co-chair of March for Science NYC. 